This manuscript is a preprint and has been submitted for publication in Earth and Planetary Science Letters (EPSL). Please note that, despite having undergone peer-review, the manuscript has yet to be formally accepted for publication. Subsequent versions of this manuscript may have slightly different content. If accepted, the final version of this manuscript will be available via the 'Peer-reviewed Publication DOI' link on the right-hand side of this webpage. Please feel free to contact any of the authors; we welcome feedback. 


\section{The 2018 Fiji $M_{w} 8.2$ and 7.9 deep earthquakes: one doublet in two}

\section{2 slabs}

3 Zhe Jia ${ }^{1}$, Zhichao Shen ${ }^{1}$, Zhongwen Zhan ${ }^{1 *}$, Chenyu Li $^{2}$, Zhigang Peng ${ }^{2}$, Michael Gurnis ${ }^{1}$

$4 \quad{ }^{1}$ Seismological Laboratory, California Institute of Technology, Pasadena, CA 91125, USA.

$5 \quad{ }^{2}$ School of Earth and Atmospheric Sciences, Georgia Institute of Technology, Atlanta, GA 30332, USA.

*Corresponding author. E-mail: zwzhan@caltech.edu

The cold Fiji-Tonga subduction zone accounts for $>75 \%$ of cataloged deep earthquakes but none of the largest ten in the last century. On 19 August 2018 and 06 September 2018, a deep earthquake doublet with moment magnitude $\left(M_{w}\right) 8.2$ and 7.9 struck the Fiji area,

11 providing a rare opportunity to interrogate the behaviors of great deep earthquakes in cold 12 slabs. By cursory examination, the doublet rupture dimensions and aftershocks are similar 13 to the 1994 Bolivia $M_{w} 8.2$ earthquake in a warm slab, instead of the 2013 Okhotsk $M_{w} 8.3$

14 event in a cold slab. This appears to contradict the traditional view that slab temperature controls deep earthquakes. However, we find that neither event was confined within the cold Tonga slab core: the $M_{w} 8.2$ ruptured mostly in the warmer rim of the Tonga slab and the $M_{w} 7.9$ occurred in a warm relic slab leaning on top of the Tonga slab. The Fiji doublet demonstrates local slab temperature as the critical factor for deep earthquakes, and reveals complex interaction of subducted slabs in Tonga. 


\section{Introduction}

Since the discovery of deep earthquakes below $300 \mathrm{~km}$ in the 1920s, the Fiji-Tonga subduction zone has produced more than $75 \%$ of global deep seismicity above magnitude 4 , but none of the ten largest deep earthquakes (Houston, 2015). This deficit of large events is reflected in FijiTonga's higher Gutenberg-Richter $b$ value than in other subduction zones (Wiens and Gilbert, 1996; Zhan, 2017), and was commonly attributed to its colder slab with older incoming plate and faster plate convergence (Wiens and Gilbert, 1996; Wiens, 2001). On August 19th, 2018, the first instrumentally recorded $M>8$ Fiji deep earthquake occurred (Fig. 1A), with a centroid depth of $556 \mathrm{~km}$ (Fig. S1) and a moment magnitude $\left(\mathrm{M}_{\mathrm{w}}\right)$ 8.2, slightly smaller than the 1994 Bolivia $\mathrm{M}_{\mathrm{w}} 8.2$ earthquake, the second largest deep earthquake after the 2013 Okhotsk $\mathrm{M}_{\mathrm{w}} 8.3$ earthquake (Table S1). The $\mathrm{M}_{\mathrm{w}}$ 8.2 Fiji event produced hundreds of aftershocks, elevating seismic activity within a few hundred kilometers. On September $6^{\text {th }}$, a $M_{w} 7.9$ earthquake occurred about $250 \mathrm{~km}$ to the west at $655 \mathrm{~km}$ depth (Fig. S1), being the second largest deep earthquake in the Fiji-Tonga region. Background seismicity in the $\mathrm{M}_{\mathrm{w}} 7.9$ source area had been minimal but increased substantially since the $M_{w} 8.2$ earthquake (Fig. 1B). Presumably, the $M_{w} 8.2$ event triggered the $\mathrm{M}_{\mathrm{w}}$ 7.9, forming the first magnitude 8 (M8) deep earthquake doublet (Tibi et al., 2003b; Ye et al., 2016).

The Fiji deep doublet and their aftershocks provide a unique opportunity to test our understanding of the still enigmatic deep earthquake mechanism, especially the properties of great deep earthquakes in cold slabs. The primary control on deep earthquakes appears to be slab temperature, which is often represented by the thermal parameter $\phi=a * v * \sin \theta$, where $\theta$ is slab dip, $a$ is incoming plate age, and $v$ is plate convergence rate (Kirby et al., 1991; Wiens and Gilbert, 1996). Deep earthquakes have only been detected in subduction zones with $\phi$ above 
$2000 \mathrm{~km}$, and the maximum depths of earthquakes increase monotonically with $\phi$ (Gorbatov et al., 1997). In addition to the aforementioned $b$-value difference, deep earthquakes in cold slabs are substantially more productive in aftershocks than those in warm slabs (Wiens and Gilbert, 1996). Rupture processes of large deep earthquakes also show systematic dependence on slab temperature (Tibi et al., 2003a). For example, the 2013 Okhotsk $M_{w} 8.3$ earthquake in the cold Kuril subduction zone $(\phi \sim 6000 \mathrm{~km})$ had higher rupture speed, lower stress drop, and higher seismic radiation efficiency (i.e., lower dissipation) than the 1994 Bolivia $\mathrm{M}_{\mathrm{w}} 8.2$ event in the warm South America subduction zone ( $\phi \sim 2000 \mathrm{~km})$ (Zhan et al., 2014). Large deep earthquakes in the cold Fiji-Tonga subduction zone $(\phi \sim 8000 \mathrm{~km})$ may then be expected to be more brittle in rupture, more efficient in seismic energy radiation, and to produce more aftershocks. To evaluate these properties, we analyze the source processes of the 2018 Fiji doublet through modeling of seismic observations, and compare their rupture properties, aftershock productivities and thermal environments with previous large deep earthquakes.

\section{Rupture properties of the Fiji doublet}

In this section, we estimate the radiated seismic energy of the Fiji doublet based on body-wave magnitudes $\left(m_{B}\right)$, determine focal mechanisms of their initial ruptures through P-wave firstmotion polarities, and image the rupture processes through subevent inversion of globally observed seismograms.

\subsection{Radiated seismic energy and radiation efficiency}

Here we use an empirical approach that converts global estimates of body wave magnitude mB to radiated energy $E_{R}$ (Gutenberg and Richter, 1956; Kanamori and Ross, 2018). We use teleseismic (from $30^{\circ}$ to $80^{\circ}$ ) vertical component seismograms on the Global Seismic Network 
(GSN) and the international Federation of Digital Seismograph Networks (FDSN) stations from IRIS DMC (Incorporated Research Institutions for Seismology Data Management Center) to estimate the body-wave magnitude $m_{B}$. After removing the instrumental responses, we convolve the displacement seismograms with the Wiechert-type instrumental response. Then, we measure the $\mathrm{P}$ wave peak amplitude and period $\left(T_{p}\right)$ and correct for the instrument gain at the period of the peak phase to determine the ground motion amplitude $\left(A_{p}\right)$. The body-wave magnitude $m_{B}$ at each station is calculated by

$$
m_{B}=\log _{10}\left(\frac{A_{p}}{T_{p}}\right)+Q(\Delta, h)
$$

where $Q$ is an empirical function of epicentral distance $\Delta$ and earthquake depth $h$ (Kanamori and Ross, 2018). The final body-wave magnitude is the median value of $m_{B}$ from all stations. We related the body-wave magnitude $m_{B}$ to radiated seismic energy $E_{R}$ using an empirical equation (Gutenberg and Richter, 1956; Kanamori and Ross, 2018):

$$
\log _{10} E_{R}=5.8+2.4 m_{B}
$$

where $E_{R}$ is in ergs. Kanamori and Ross (2018) verified the accuracy of the above equation by comparing with previous radiated energy estimates and found differences within a factor of two for deep earthquakes. Once the radiated seismic energy is obtained, the scaled energy can be computed with $E_{R} / M_{0}$, where $M_{0}$ is the seismic moment from the Global CMT catalog (www.globalcmt.org).

We find that the radiated energy estimates for the Fiji doublet are not substantially higher than for previous M8 deep earthquakes: $1.29 \times 10^{24} \mathrm{ergs}$ and $2.31 \times 10^{23} \mathrm{ergs}$ for the $\mathrm{M}_{\mathrm{w}} 8.2$ and $\mathrm{M}_{\mathrm{w}}$ 7.9 earthquakes, respectively (Table 1). In comparison, our estimated $E_{R}$ for the 1994 Bolivia and the 2013 Okhotsk earthquakes are $1.42 \times 10^{24} \mathrm{ergs}$ and $1.72 \times 10^{24} \mathrm{ergs}$, consistent with 

previous measurements (Kanamori et al., 1998; Ye et al., 2013). After normalization by their seismic moments $M_{0}$, there is no substantial difference in the scaled energy $E_{R} / M_{0}$ for all four events (Table 1), given the uncertainties of $E_{R}$. Therefore, the Fiji events, although in the world's coldest subduction zone, did not radiate more seismic energy than events in warmer subduction zones. Further comparison of radiation efficiency $\eta_{R}=E_{R} / \Delta W_{0}$ requires estimating the available strain energy $\Delta W_{0}=M_{0} \Delta \sigma / 2 \mu$, and stress drop $\Delta \sigma \propto M_{0} / L^{3}$ is highly sensitive to the earthquake rupture dimension $L$. Hence, to quantify whether the Fiji doublet are more seismically efficient than previous large deep earthquakes in warmer subduction zones, we need to constrain the rupture dimensions of these earthquakes consistently.

\subsection{First-motion focal mechanisms}

To gain insights on possible ruptures complexities, we first investigate the initiations of the Fiji doublet ruptures, by examining their first-motion focal mechanisms relative to the centroid moment tensors. We manually pick the first arrivals of broadband $\mathrm{P}$ waves on both regional and teleseismic stations, identify their polarities, and determine the geometries of nodal planes. Fig. 2 shows the observed P-wave polarities and the estimated first-motion mechanisms (solid lines and shades), with substantial differences from the best-fitting double-couple mechanisms based on the Global CMT solutions (dashed lines). For the $\mathrm{M}_{\mathrm{w}} 8.2$ earthquake, the difference in focal mechanism (strike/dip of $56^{\circ} / 80^{\circ}$ vs. $13^{\circ} / 70^{\circ}$ ) is mostly due to the positive polarities observed at stations to the southwest (SW) directions (Fig. 2A). Polarity observations of the $\mathrm{M}_{\mathrm{w}} 7.9$ earthquake indicate a strike-slip mechanism, with two nodal planes of strike/dip $=38^{\circ} / 85^{\circ}$ and $128^{\circ} / 80^{\circ}$, both of which deviates substantially from the double-couple component of the Global CMT solution ( strike/dip $=305^{\circ} / 57^{\circ}$ and $207^{\circ} / 77^{\circ}$ ) (Fig. 2B). The differences between the first- 
motion mechanisms and the centroid mechanisms indicates substantial changes in fault geometry or rake angle during the ruptures of the Fiji doublet, which we accommodate in the subevent

113 inversions.

\subsection{Rupture processes and aftershocks}

115 We image the doublet rupture processes and dimensions by subevent inversions. Our subevent inversion method parameterizes a large earthquake as a series of point sources (subevents) and uses teleseismic $\mathrm{P}, \mathrm{SH}$, and $\mathrm{pP}$ waveforms to constrain properties of individual subevents. It is similar to a previous method applied to the 1994 Bolivia and 2013 Okhotsk earthquakes (Zhan et al., 2014), but includes subevent focal mechanisms explicitly to quantify changes of radiation pattern along rupture. Furthermore, $\mathrm{pP}$ depth phases added to the inversion help resolve possible variations in subevent depths. In this method, we invert for the centroid locations, centroid times, durations, and moment tensors of all subevents. Our method combines non-linear inversion for a subset of parameters and linear inversion for the rest. We apply Markov Chain Monte Carlo (MCMC) method to sample the posterior Probability Density Functions (PDFs) of the nonlinear parameters including the timings, locations, and durations of subevents. For a given set of subevent timings, locations, and durations (i.e., one MCMC sample), we evaluate the apparent source time function for each station, and linearly invert the seismic data for the subevent moment tensors. The data misfit from the set of nonlinear parameters and the corresponding moment tensor solutions is then used to estimate the probability in the MCMC inversion.

130 Compared with a fully non-linear inversion scheme, this hybrid approach requires much less

131 computation to search the parameter space, hence provides more robust solutions. The number of

132 subevents increases iteratively until the waveforms are fit well. More details of our subevent

133 method can be found in the supplementary material. 
The subevent model for the $\mathrm{M}_{\mathrm{w}} 8.2$ earthquake (Fig. 3A, Fig. S2, Table S2) shows two stages of rupture. The first stage includes subevent E1 (centroid time $\left.\tau_{C}=8.15 \mathrm{~s}, \mathrm{M}_{\mathrm{w}} 7.55\right)$, E2 ( $\tau_{C}=10.88 \mathrm{~s}$, $\mathrm{M}_{\mathrm{w}}$ 7.66), and E3 ( $\left.\tau_{C}=13.16 \mathrm{~s}, \mathrm{M}_{\mathrm{w}} 7.61\right)$, aligned approximately in the NE direction with similar focal mechanisms (average strike $/$ dip $/$ rake $\left.=43^{\circ} / 84^{\circ} /-77^{\circ}, 160^{\circ} / 18^{\circ} /-152^{\circ}\right)$. E1's focal mechanism from waveform inversion confirms the first-motion polarities of teleseismic $\mathrm{P}$ waves (Fig. 2A). Posterior Probability Density Functions (PDFs) of the subevent depths suggest that E3 is about $15 \mathrm{~km}$ shallower than E1 and E2 (Fig. S3), preferring the stage 1 rupture to be on the steep NE-strike fault plane ( $\operatorname{strike} / \operatorname{dip}=43^{\circ} / 84^{\circ}$ ), which is also supported by the nearly vertical band of aftershocks (Fig. 4A). The largest subevent of stage 1, E2, appears to have triggered large slip on multiple faults in stage 2. Subevents E4 ( $\left.\tau_{C}=14.88 \mathrm{~s}, \mathrm{M}_{\mathrm{w}} 7.81\right)$, E5 $\left(\tau_{C}=17.47 \mathrm{~s}, \mathrm{M}_{\mathrm{w}}\right.$ 7.72) and $\mathrm{E} 6\left(\tau_{C}=20.81 \mathrm{~s}, \mathrm{M}_{\mathrm{w}} 7.83\right)$ are aligned towards the northwest (NW) and they have relatively similar focal mechanisms (average strike/dip $/$ rake $=3^{\circ} / 71^{\circ} /-100^{\circ}, 213^{\circ} / 23^{\circ} /-63^{\circ}$ ). The difference in radiation pattern between the two stages (Fig. 2A) is evident on the teleseismic Pwave displacement seismograms with flipping polarities (Fig. 3B, Fig. S4). Posterior PDFs suggest that E2, E4, E5, and E6 rupture sequentially towards shallower depths by about $30 \mathrm{~km}$ (Fig. 4B, Fig. S3), rejecting the shallow west-dipping nodal plane (strike/dip=213\% $/ 23^{\circ}$ ) as the rupture plane. Furthermore, as E2, E4, E5, and E6 centroid locations are not aligned in the northsouth (N-S) direction, it is also unlikely that they occurred on the N-S striking, steep fault plane $\left(\right.$ strike $\left./ \operatorname{dip}=3^{\circ} / 71^{\circ}\right)$. This disagreement between the subevent strikes and the alignment of their locations is also confirmed by a simpler three-subevent model (Fig. 5), in which the two main subevents E2 and E3 are aligned from SE to NW, being located shallower, while their strikes are north. Therefore, we conclude that the stage 2 rupture must involve multiple faults, although the 
exact geometry is uncertain (e.g., en echelon vs. perpendicular faults). Previous magnitude 7 deep earthquakes in Fiji-Tonga show a diversity of fault geometries (Warren et al., 2007). The sum of the subevent moment tensors explains the long period moment tensor solution of the $\mathrm{M}_{\mathrm{w}}$ 8.2 earthquake well, including the $\sim 10 \%$ non-double-couple (non-DC) component (Fig. S2). The overall subevent dimension of stage 2 is $\sim 30 \mathrm{~km}$, about the same as stage 1 but with much larger total moment. The two stages altogether contribute to a total rupture dimension of $\sim 50 \mathrm{~km}$, consistent with the three-subevent model (Fig. 5). To further confirm whether the estimation of rupture dimension is insensitive to our specific subevent parameterization and choice of number of subevents, we conduct another inversion approximating the earthquake as a single Haskell source. The result is a unilateral rupture towards the NW with a length close to $60 \mathrm{~km}$, roughly consistent with the values from subevent inversions. However, the Haskell source model cannot capture the distribution of moment along rupture, or the changes in depth and moment tensor.

168 The $\mathrm{M}_{\mathrm{w}} 8.2$ earthquake produced over $400 \mathrm{M}>4$ aftershocks during the following 80 days, more

169 than any previous deep earthquake. In comparison, the 2013 Okhotsk and 1994 Bolivia earthquakes produced 71 and $4 \mathrm{M}>4$ aftershocks in the same duration, respectively. After correcting for differences in catalog completeness and mainshock magnitudes (Utsu and Ogata, 1995; Peng et al., 2007), the aftershock productivity of the $2018 \mathrm{Fiji}_{\mathrm{w}} 8.2$ is similar to the 1994 Fiji $M_{\mathrm{w}} 7.6$ earthquake, and significantly higher than other large deep earthquakes (Fig. 6).

174 However, the distribution of the Fiji $\mathrm{M}_{\mathrm{w}} 8.2$ aftershocks is non-uniform and does not follow the mainshock slip distribution. Here we relocate the $\mathrm{M}_{\mathrm{w}} 8.2$ main shock and its aftershock using a

176 teleseismic double difference algorithm (Pesicek et al., 2010). More details can be found in the

177 supplementary materials. The aftershocks concentrated in a NE-strike band, aligned with the

178 inferred fault plane for the stage 1 rupture but are sparser around the stage 2 rupture (Fig. 3A, 4A; 
Fig. S8-S9), which accounts for most of the total moment. This suggests that the aftershock productivities of the two stages of the $\mathrm{M}_{\mathrm{w}} 8.2$ are substantially different.

The $\mathrm{M}_{\mathrm{w}} 7.9$ event of the Fiji doublet has $\sim 30 \%$ non-double-couple (non-DC) component in the USGS WPhase and the Global CMT solutions, compared with $\sim 10 \%$ for the $\mathrm{M}_{\mathrm{w}} 8.2$ event. This large non-DC is reflected by the diverse subevent focal mechanisms we derived from waveforms (Fig. 3A, Fig. S10-S13, Table S3), and supported by the deviation of polarity-based focal mechanism from the best-fitting double-couple of the Global CMT solution (Fig. 2). The earthquake first ruptured to the east (E1-E2), then the major subevents (E3 to E6) occurred in a cluster from SW to NE direction (Fig. 3A). Given the uncertainty of subevent locations and focal mechanisms, it is unclear whether they ruptured on a single NE-strike fault plane or as a cascade of ruptures on multiple faults (Fig. S10). By including both teleseismic depth phases $(p P)$ and the up-going direct $\mathrm{P}$ and SH waveforms recorded by a local station MSVF in our inversion, we find that the $\mathrm{M}_{\mathrm{w}} 7.9$ event ruptured a $20 \mathrm{~km}$ depth range (Fig. S11-S14). The largest four subevents from E3 to E6 account for $\sim 90 \%$ of the total moment and are concentrated within $40 \mathrm{~km}$ from each other laterally (Fig. 3A), comparable to the subevent dimension of the $\mathrm{M}_{\mathrm{w}} 8.2$ event's stage 2 rupture.

\section{Implications for temperature dependence of deep earthquakes}

The rupture dimensions of the Fiji doublet from our subevent models seem to contradict the expectation of higher radiation efficiency for large deep earthquakes in a cold subduction zone. Fig. 7 displays five large deep earthquakes' subevent models at the same scale, all derived from consistent methodology for comparison. The Fiji doublet's rupture dimensions are similar to that of the 1994 Bolivia earthquake in the warm South American subduction zone and substantially smaller than the 2013 Okhotsk earthquake in the cold Kuril subduction zone. With $E_{R} / M_{0}$ for all 
these large deep earthquakes being similar to each other (Table 1), the radiation efficiency $\left(\eta_{R}\right)$ estimates depend strongly on the rupture dimensions $(L), \eta_{R} \propto \Delta \sigma^{-1} \propto L^{3} / M_{0}$ However, both the $M_{w} 8.2$ and the $M_{w}$ 7.9 Fiji events may have ruptured more than one fault, which makes the definition of rupture dimension or even the applicability of the stress drop scaling $\Delta \sigma \propto M_{0} / L^{3}$ questionable. Furthermore, the rupture dimensions on individual faults are poorly constrained without clear subevent directivity. This is a fundamental limitation of observing the sources from far field. Nevertheless, if we take the overall area in which subevents, especially the ones with the largest moments, are located as a proxy of the rupture dimension, the relatively compact rupture dimensions of the Fiji doublet suggest inefficient ruptures in terms of seismic radiation, despite being in the world's coldest subduction zone. This seems to contradict the view that slab temperature is the primary control on the rupture behaviors of deep earthquakes.

However, a more detailed comparison of the Fiji $\mathrm{M}_{\mathrm{w}} 8.2$ subevent model and the distribution of background seismicity suggest that the main rupture was not confined to the cold core of the Tonga slab, but occurred mostly in the warmer portion of the slab. Background deep seismicity is generally assumed to represent the cold brittle core of slabs (Antolik et al., 1999; Wiens, 2001).

217 This assumption is supported by observations in areas with high-resolution tomography models 218 and earthquake locations, such as the Japan subduction zone (Tao et al., 2018). In northern Fiji219 Tonga, background seismicity forms a southeast (SE)-strike, steeply dipping band (Fig. 3A, 4B).

220 Wiens et al. (1993) reported a deep double seismic zone with a refined regional catalog and 221 further interpreted as top and bottom edges of a metastable olivine wedge in the cold slab core. 222 They also noticed that the $1994 \mathrm{M}_{\mathrm{w}} 7.6$ Fiji deep earthquake (Fig. 1A), $40 \mathrm{~km}$ NW of the 2018 $223 \mathrm{M}_{\mathrm{w}} 8.2$ event, started within the background seismic band but ruptured outside the band to the 224 north and northeast. We confirm this observation with our subevent model for the 1994 Fiji event, 
with a $\mathrm{M}_{\mathrm{w}} 7.3$ subevent $\mathrm{E} 1$ in the center of the seismic band and a $\mathrm{M}_{\mathrm{w}} 7.4$ subevent $\mathrm{E} 2$ towards northern edge of the band (Fig. 3A, Fig. 7, Table S4). The $2018 \mathrm{M}_{\mathrm{w}} 8.2$ earthquake had a similar rupture process but was more complicated. It initiated near the center of the background seismicity band and ruptured on a nearly vertical fault perpendicular to the slab strike toward the northeast (NE), away from the slab core. The second stage of rupture (E2, E4 6), which accounts for most of the moment, all ruptured near the edge of the background seismic band, about $30 \mathrm{~km}$ away from the center line (Fig. 3). Thermal modeling of the subducted Tonga slab suggests that the temperature around the stage 2 rupture would be $\sim 900{ }^{\circ} \mathrm{C}, 200{ }^{\circ} \mathrm{C}$ warmer than the center

(Fig. 8B). This inferred temperature difference for the two rupture stages is also supported by the distribution of aftershocks, with most aftershocks around the lower-moment stage 1 near slab center (Fig. 3A). The temperature dependence of deep aftershock productivity has been observed in many subduction zones (Wiens and Gilbert, 1996), but is happening within the Fiji $\mathrm{M}_{\mathrm{w}} 8.2$ between the cold core and warm slab rim.

The $\mathrm{M}_{\mathrm{w}} 7.9$ earthquake, on the other hand, appears to occur within the relic Fiji slab, which is

239 overall warmer than the adjacent Tonga slab. This event is a good example of so-called "isolated 240 large deep earthquakes" that occur in region with little background seismicity and produce very 241 few aftershocks (Lundgren and Giardini, 1994). The $\mathrm{M}_{\mathrm{w}} 7.9$ event produced much fewer 242 aftershocks than the $M_{w} 8.2$ earthquake (Fig. 6), especially if we only consider those within the mainshock rupture area (Fig. 7). Other examples of isolated events include the $1954 \mathrm{M}_{\mathrm{w}} 7.9$

244 Spain, the $1970 \mathrm{M}_{\mathrm{w}} 8.0$ Colombia, and the $2015 \mathrm{M}_{\mathrm{w}} 7.9$ Bonin Islands earthquakes. It is proposed 245 that isolated deep earthquakes occur in warm or remnant slabs that have difficulty nucleating 246 spontaneously. But once started or triggered, isolated deep earthquakes can rupture and 247 completely release the high stress accumulated over time, therefore leaving little residual stress 

earthquake occurred where the relic Fiji slab has been long inferred, based on seismicity/focal mechanisms, tomographic models, and geodynamic investigation of the tectonic history (Chen and Brudzinski, 2001; Brudzinski and Chen, 2003; Richards et al., 2011). In particular, both regional (Conder and Wiens, 2006) and global (Fukao and Obayashi, 2013) models show a high velocity zone above the Tonga slab (Fig. 8A). The $2009 \mathrm{M}_{\mathrm{w}} 7.3$ Fiji deep earthquake (Fig. 1A) also triggered aftershocks that illuminated the normally aseismic relic slab (Cai and Wiens, 2016). The remnant slab presumably subducted from the initiation of the Vanuatu trench approximately 15 million years (Ma) ago (Seton et al., 2012). The consumed Australian plate would have been formed earlier by the rapid eastward migration of the Tonga subduction zone that initiated at $\sim 50 \mathrm{Ma}$. Consequently, the lithosphere of the remnant slab would have been about $\sim 35$ Ma old (see supplementary material for details). Thermal modeling shows that the coldest core of such remnant slab would be $\sim 1000{ }^{\circ} \mathrm{C}$, similar to the warm South America slab

261 and the warmer rim of the Tonga slab where the Fiji $\mathrm{M}_{\mathrm{w}} 8.2$ stage 2 rupture occurred (Fig. 8B-

$2628 D$, Fig. S15). Therefore, we propose that the $\mathrm{M}_{\mathrm{w}} 7.9$ earthquake occurred in the relic Fiji slab.

263 The agreements in temperature consistently explain the low background seismicity, compact 264 subevent locations, and low aftershock productivity of the 1994 Bolivia $\mathrm{M}_{\mathrm{w}}$ 8.2, 2018 Fiji $\mathrm{M}_{\mathrm{w}}$ 2657.9 , and the stage 2 rupture of the 2018 Fiji $\mathrm{M}_{\mathrm{w}} 8.2$ events.

\section{Discussion}

267 Recently Fan et al. (2019) applied teleseismic back projection to the Fiji $\mathrm{M}_{\mathrm{w}} 8.2$ event and 268 estimated that the rupture extended $\sim 100 \mathrm{~km}$ to the north from the hypocenter, accompanied with 269 changing focal mechanisms and rupture directions. Our source models of the $\mathrm{M}_{\mathrm{w}} 8.2$ event (Fig. 5) confirm the two-stage rupture with different directivity and the first stage on a vertical fault 
plane producing most of the aftershocks, consistent with Fan et al. (2019) 's result. However, the last subevent in our model is located $\sim 50 \mathrm{~km}$ to the north of the hypocenter, indicating substantially more compact rupture dimension (50-60 km; Fig. 5) than the estimate of 110-150 $\mathrm{km}$ in Fan et al. (2019). This difference results in non-trivial difference in average stress drop and the temperature range of slab over which the $\mathrm{M}_{\mathrm{w}} 8.2$ event ruptured (Fig. S16). The sum of the six subevent moment tensors has a moment of $2.57 \times 10^{28}$ dyne $-\mathrm{cm}$, close to the Global CMT moment $\left(2.52 \times 10^{28}\right.$ dyne $\left.-\mathrm{cm}\right)$, suggesting that we are not missing any major subevent in our model. The difference in rupture dimension between our study and Fan et al. (2019) may be due to frequency dependent seismic radiation, as commonly observed for shallow megathrust earthquakes (Koper et al., 2011; Yao et al., 2013). Back projection method tracks the radiators of high-frequency energy, while the subevent inversion images the spatial distribution of seismic moment or slip. Therefore, a subevent with strong high-frequency radiation but low moment may be missed in our models. While such a subevent may significantly change the estimation of total rupture dimension and apparent rupture speed, it is unclear whether it should be included in stress drop or radiation efficiency calculations.

286 Earthquakes are often assumed to rupture on a single fault, although in recent years more near 287 field data and high-resolution aftershock patterns have revealed complicated faulting geometry 288 for several large shallow earthquakes (e.g., 2012 Sumatra, 2016 Kaikoura) (Yue et al., 2012; 289 Hamling et al., 2017). Resolving fault plane(s) for deep earthquakes with only far-field seismic 290 data is challenging. In this paper, we take the discrepancy between subevent focal mechanisms 291 and locations (Fig. 3, Fig. 5) in our subevent models of the Fiji $\mathrm{M}_{\mathrm{w}} 8.2$ earthquake as evidences 292 for rupture over multiple faults during stage 2, though it is unclear how the rupture 293 propagates/jumps though these faults. Another example of multiple-fault rupture of deep 
earthquakes was suggested by Chen et al. (2014), where they found the subevents of the 2013

Okhotsk $\mathrm{M}_{\mathrm{w}} 8.3$ earthquake cannot be fit onto a planar fault. This kind of rupture complexity

challenges the conventional interpretation of deep earthquake properties. For example, an average rupture velocity estimated from either subevent modeling, teleseismic back-projection, or finite-fault inversion assuming a simplified fault geometry may not reflect the true source dynamics. The rupture velocity is defined by propagation of the rupture front, but one might approximate it by the subevent centroid migration speed instead. The centroidal rupture speeds $V_{c r}$ of the $M_{w} 8.2$ event, considering the subevent depth variations, are about $4.5 \mathrm{~km} / \mathrm{s}$ (Fig. S17) for both stages. However, we believe only the stage $1 \mathrm{~V}_{\text {cr }}$ is related to a continuous rupture on a vertical fault plane, and the relatively high speed is consistent with the interpretation that the $\mathrm{M}_{\mathrm{w}}$

3048.2 event initiated in the cold slab core. On the other hand, because our far-field seismic data

305 cannot resolve the rupture speeds of individual subevents, the stage $2 \mathrm{~V}_{\text {cr }}$ may represent static/dynamic triggering among subevents on different faults (Tibi et al., 2003b; Wei et al., 2013;

307 Chen et al., 2014; Zhan and Shearer, 2014; Cai and Wiens, 2016). This dilemma also applies to 308 the $\mathrm{M}_{\mathrm{w}} 7.9$ event, for which $\mathrm{V}_{\mathrm{cr}}$ is $\sim 3.1 \mathrm{~km} / \mathrm{s}$ for the major subevents (Fig. S18) but we cannot 309 define a clear fault plane. Therefore, the subevent rupture speeds of the doublet, which are more

310 important than $\mathrm{V}_{\text {cr }}$ for the estimation of stress drops and radiation efficiency, are not well 311 constrained and need further investigations.

\section{5. Conclusions}

313 In summary, the 2018 Fiji doublet reflects the complex interaction of slabs near the bottom of the mantle transition zone. The relic Fiji slab sank through the mantle wedge, with one end leaning onto the underlying Tonga slab and deforming the cold/brittle Tonga slab core, producing 
Fiji slab is under sub-horizontal compression, but has difficulty nucleating and releasing the stress seismically due to the lack of a brittle cold core. Most previous deep earthquakes in the Tonga slab are confined to the brittle core, or only rupture partially outside in some of the larger events (e.g., 1994 Fiji $\mathrm{M}_{\mathrm{w}}$ 7.6). The $2018 \mathrm{M}_{\mathrm{w}} 8.2$ event triggered large and complex ruptures in the warmer portion of slab and generated strong static/dynamic stress perturbations in the surrounding area, including the relic Fiji slab. Three weeks later, one of the triggered events in the relic slab succeeded in cascading into a $\mathrm{M}_{\mathrm{w}} 7.9$ event and released the high stress accumulated over time. Although the Fiji doublet occurred in the world's coldest subduction zone, neither was confined to the cold core of the Tonga slab. Therefore, their unexpected behaviors in terms of rupture dimension, radiation efficiency, and aftershocks support, not contradict, the traditional view that temperature is the main control on deep earthquakes. This emphasizes the importance of detailed mapping of deep earthquake ruptures along with the

329 thermal structure implied by the tectonic evolution of the margin.

\section{Acknowledgements}

331 We thank Yunyi Qian for sharing the Multitel3 code. We thank Stephen C. Myers and Douglas

332 Wiens for sharing the aftershock catalog of 1994 Bolivia and 1994 Tonga earthquakes, and

333 Lingsen Meng for sharing their unpublished result. We thank Hiroo Kanamori, Chen Ji and

334 Robert Clayton for helpful discussions. We thank three anonymous reviewers and editor Miaki

335 Ishii for their helpful comments. Seismic recordings are from the IRIS data management center.

336 The earthquake catalogs are from the U.S. Geological Survey (USGS) National Earthquake

337 Information Center (NEIC) and the International Seismological Center (ISC). This work is 338 supported by USGS grant G19AP00030. C.L. and Z.P. are partially supported by NSF grants 339 EAR-1818611 and EAR-1925965. 


\section{References}

Antolik, M., Dreger, D., Romanowicz, B., 1999. Rupture processes of large deep-focus earthquakes from inversion of moment rate functions. J. Geophys. Res. 104, 863-894.

Brudzinski, M.R., Chen, W.P., 2003. A petrologic anomaly accompanying outboard earthquakes beneath Fiji-Tonga: Corresponding evidence from broadband $\mathrm{P}$ and $\mathrm{S}$ waveforms. Journal of Geophysical Research: Solid Earth 108, B6.

Cai, C., Wiens, D.A., 2016. Dynamic triggering of deep earthquakes within a fossil slab. Geophys. Res. Lett. 43, 9492-9499.

Chen, W.P., Brudzinski, M.R., 2001. Evidence for a large-scale remnant of subducted lithosphere beneath Fiji. Science 292, 2475-2479.

Chen, Y., Wen, L., Ji, C., 2014. A cascading failure during the 24 May 2013 great Okhotsk deep earthquake. J. Geophys. Res. 119, 3035-3049.

Conder, J.A., Wiens, D.A., 2006. Seismic structure beneath the Tonga arc and Lau back-arc basin determined from joint Vp, Vp/Vs tomography. Geochem. Geophys. Geosyst. 7, 3.

Fan, W., Wei, S.S., Tian, D., McGuire, J.J., Wiens, D.A., 2019. Complex and Diverse Rupture Processes of the $2018 \mathrm{Mw} 8.2$ and M w 7.9 Tonga-Fiji Deep Earthquakes. Geophys. Res. Lett. 46, 2434-2448.

Frohlich, C., 2006. Deep earthquakes. Cambridge University Press, Cambridge, UK. Fukao, Y., Obayashi, M., 2013. Subducted slabs stagnant above, penetrating through, and trapped below the $660 \mathrm{~km}$ discontinuity. J. Geophys. Res. 118, 5920-5938. 
Gorbatov, A., Kostoglodov, V., Suárez, G., Gordeev, E., 1997. Seismicity and structure of the

Kamchatka subduction zone. Journal of Geophysical Research: Solid Earth 102, 17883-17898.

Gutenberg, B., Richter, C.F., 1956. Earthquake magnitude, intensity, energy, and acceleration:

Hamling, I.J., Hreinsdóttir, S., Clark, K., Elliott, J., Liang, C., Fielding, E., Litchfield, N.,

Hayes, G.P., Moore, G.L., Portner, D.E., Hearne, M., Flamme, H., Furtney, M., Smoczyk, G.M.,

371 Kanamori, H., Anderson, D.L., Heaton, T.H., 1998. Frictional melting during the rupture of the 3721994 Bolivian earthquake. Science 279, 839-842.

373 Kanamori, H., Ross, Z.E., 2018. Reviving mB. Geophys. J. Int 216, 1798-1816.

374 Kirby, S.H., Durham, W.B., Stern, L.A., 1991. Mantle phase changes and deep-earthquake 375 faulting in subducting lithosphere. Science 252, 216-225.

376 Kirby, S.H., Stein, S., Okal, E.A., Rubie, D.C., 1996. Metastable mantle phase transformations 377 and deep earthquakes in subducting oceanic lithosphere. Rev. Geophys. 34, 261-306.

378 Koper, K.D., Hutko, A.R., Lay, T., Ammon, C.J., Kanamori, H., 2011. Frequency-dependent 379 rupture process of the $2011 \mathrm{M} \mathrm{w} 9.0$ Tohoku Earthquake: Comparison of short-period P wave 380 backprojection images and broadband seismic rupture models. Earth, planets and space 63, 16. 
Lundgren, P., Giardini, D., 1994. Isolated deep earthquakes and the fate of subduction in the mantle. J. Geophys. Res. 99, 15833.

Myers, S.C., Wallace, T.C., Beck, S.L., Silver, P.G., Zandt, G., Vandecar, J., Minaya, E., 1995. Implications of spatial and temporal development of the aftershock sequence for the Mw 8.3 June 9, 1994 deep Bolivian earthquake. Geophys. Res. Lett. 22, 2269-2272.

Peng, Z., Vidale, J.E., Ishii, M., Helmstetter, A., 2007. Seismicity rate immediately before and after main shock rupture from high-frequency waveforms in Japan. Journal of Geophysical Research: Solid Earth 112, B3.

Pesicek, J., Thurber, C., Zhang, H., DeShon, H., Engdahl, E., Widiyantoro, S., 2010. Teleseismic double-difference relocation of earthquakes along the Sumatra-Andaman subduction zone using a 3-D model. Journal of Geophysical Research: Solid Earth 115, B10.

Richards, S., Holm, R., Barber, G., 2011. When slabs collide: A tectonic assessment of deep earthquakes in the Tonga-Vanuatu region. Geology 39, 787-790.

Seton, M., Müller, R., Zahirovic, S., Gaina, C., Torsvik, T., Shephard, G., Talsma, A., Gurnis, M., Turner, M., Maus, S., 2012. Global continental and ocean basin reconstructions since 200 Ma. Earth-Science Reviews 113, 212-270.

Tao, K., Grand, S.P., Niu, F., 2018. Seismic structure of the upper mantle beneath Eastern Asia from full waveform seismic tomography. Geochem. Geophys. Geosyst. 19, 2732-2763.

Tibi, R., Bock, G., Wiens, D.A., 2003a. Source characteristics of large deep earthquakes: Constraint on the faulting mechanism at great depths. J. Geophys. Res. 108, 2091. 
401

402

403

404

405

406

407

408

409

410

411

412

413

414

415

416

417

418

419

420

421

422

Tibi, R., Wiens, D.A., Inoue, H., 2003b. Remote triggering of deep earthquakes in the 2002 Tonga sequences. Nature 424, 921-925.

Utsu, T., Ogata, Y., 1995. The centenary of the Omori formula for a decay law of aftershock activity. JPE 43, 1-33.

Warren, L.M., Hughes, A.N., Silver, P.G., 2007. Earthquake mechanics and deformation in the Tonga-Kermadec subduction zone from fault plane orientations of intermediate-and deep-focus earthquakes. Journal of Geophysical Research: Solid Earth 112, B5.

Wei, S., Helmberger, D., Zhan, Z., Graves, R., 2013. Rupture complexity of theMw8.3 sea of okhotsk earthquake: Rapid triggering of complementary earthquakes? Geophys. Res. Lett. 40, 5034-5039.

Wiens, D.A., 2001. Seismological constraints on the mechanism of deep earthquakes:

temperature dependence of deep earthquake source properties. Phys. Earth Planet. Inter. 127, 145-163.

Wiens, D.A., Gilbert, H.J., 1996. Effect of slab temperature on deep-earthquake aftershock productivity and magnitude-frequency relations. Nature 384, 153-156.

Wiens, D.A., McGuire, J.J., 2000. Aftershocks of the March 9, 1994, Tonga earthquake: The strongest known deep aftershock sequence. Journal of Geophysical Research: Solid Earth 105, 19067-19083.

Wiens, D.A., McGuire, J.J., Shore, P.J., 1993. Evidence for transformational faulting from a deep double seismic zone in Tonga. Nature 364, 790-793.

Yao, H., Shearer, P.M., Gerstoft, P., 2013. Compressive sensing of frequency-dependent seismic radiation from subduction zone megathrust ruptures. Proc. Natl. Acad. Sci. 110, 4512-4517. 
423 Ye, L., Lay, T., Kanamori, H., Koper, K.D., 2013. Energy release of the 2013 Mw 8.3 Sea of

424 Okhotsk earthquake and deep slab stress heterogeneity. Science 341, 1380-1384.

425 Ye, L., Lay, T., Kanamori, H., Zhan, Z., Duputel, Z., 2016. Diverse rupture processes in the 2015

426 Peru deep earthquake doublet. Science advances 2, e1600581.

427 Yue, H., Lay, T., Koper, K.D., 2012. En échelon and orthogonal fault ruptures of the 11 April 4282012 great intraplate earthquakes. Nature 490, 245.

429 Zhan, Z., 2017. Gutenberg-Richter law for deep earthquakes revisited: a dual-mechanism

430 hypothesis. Earth Planet. Sci. Lett. 461, 1-7.

431 Zhan, Z., Kanamori, H., Tsai, V.C., Helmberger, D.V., Wei, S., 2014. Rupture complexity of the 4321994 Bolivia and 2013 Sea of Okhotsk deep earthquakes. Earth Planet. Sci. Lett. 385, 89-96.

433 Zhan, Z., Shearer, P.M., 2014. Dynamic Triggering of Deep Earthquakes—a Global Perspective, 434 abstract S32B-08 presented at the annual AGU meeting, San Francisco, 15-19 Dec. 


\section{Tables}

\begin{tabular}{|l|l|l|l|}
\hline & $\begin{array}{l}\text { Body wave } \\
\text { magnitude }\left(\mathbf{m}_{\mathrm{B}}\right)\end{array}$ & $\begin{array}{l}\text { Radiated } \\
\text { energy (Erg) }\end{array}$ & $\begin{array}{l}\text { Scaled radiated } \\
\text { energy (10-5) }\end{array}$ \\
\hline 1994 Fiji $\mathrm{M}_{\mathrm{w}} 7.5$ & $7.17(7.16)$ & $1.03 \times 10^{23}$ & $3.35(3.14)$ \\
\hline 1994 Bolivia $\mathrm{M}_{\mathrm{w}} 8.2$ & $7.65(7.65)$ & $1.42 \times 10^{24}$ & $5.41(5.53)$ \\
\hline 2013 Okhotsk $\mathrm{M}_{\mathrm{w}} 8.3$ & $7.68(7.69)$ & $1.72 \times 10^{24}$ & $4.34(4.47)$ \\
\hline 2015 Bonin $\mathrm{M}_{\mathrm{w}} 7.9$ & $7.35(7.37)$ & $2.72 \times 10^{23}$ & $3.56(4.09)$ \\
\hline 2018 Fiji $\mathrm{M}_{\mathrm{w}} 8.2$ & 7.63 & $1.29 \times 10^{24}$ & 4.89 \\
\hline 2018 Fiji $\mathrm{M}_{\mathrm{w}} 7.9$ & 7.32 & $2.31 \times 10^{23}$ & 2.68 \\
\hline
\end{tabular}

439 Table 1. Comparison of body-wave magnitude $\left(m_{B}\right)$, radiated energy, and scaled energy

440 of the six large deep earthquakes discussed in this study. Numbers in red are from

441 Kanamori and Ross (2018) as comparisons. 


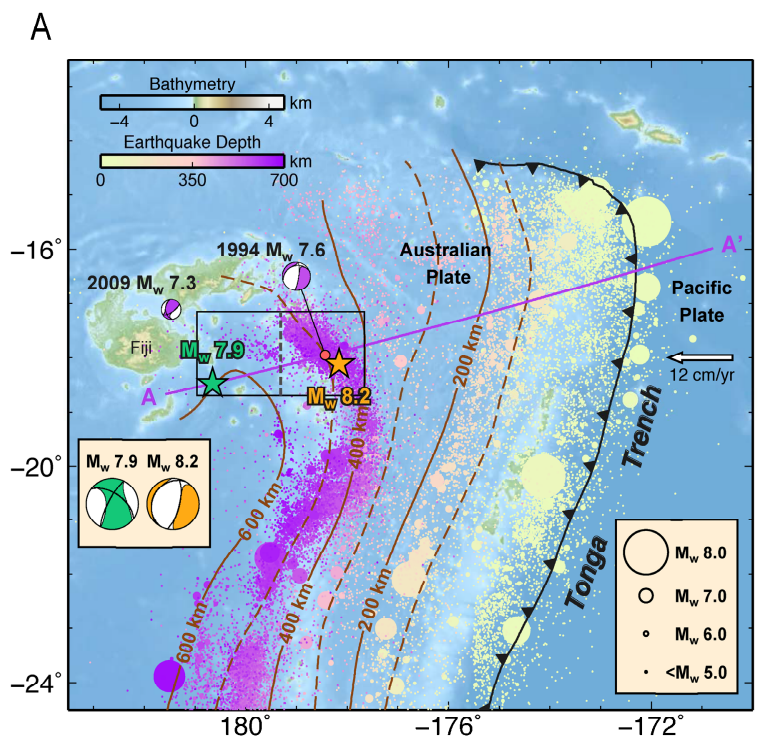

B
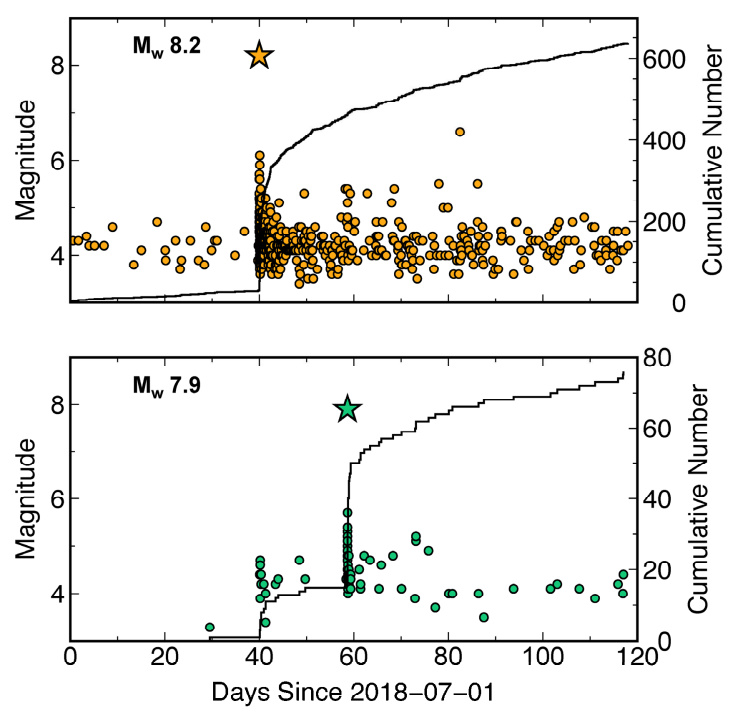

Figure 1

Fig. 1. Tectonic setting and seismicity. (A) The 2018 Fiji deep earthquake doublet $\left(M_{w} 8.2\right.$ and $M_{w}$ 7.9) occurred in the northern end of Fiji-Tonga subduction zone where the Pacific plate subducts under the Australian plate, as illustrated by the background seismicity (dots) based on the ISC catalog and the slab depth contours from the Slab 2.0 model (Hayes et al., 2018). The stars show the mainshock epicenter locations, and the mainshock moment tensors from Global CMT catalog are displayed in the inset. (B) Seismic activity around the $\mathrm{M}_{\mathrm{w}} 8.2$ and $\mathrm{M}_{\mathrm{w}} 7.9$ events in the black squares in (A) based on the ISC catalog. Body wave magnitudes are plotted except for the mainshocks. Solid black lines denote the cumulative number of aftershock in the mainshock regions (boxes in A). The $\mathrm{M}_{\mathrm{w}} 8.2$ event triggered hundreds of aftershocks near its 
454 rupture area and also elevated activity in the source region of the later $M_{w} 7.9$ event, during the

455 three weeks in between. The $\mathrm{M}_{\mathrm{w}} 7.9$ event produced another tens of aftershocks around its 456 rupture area.

457 

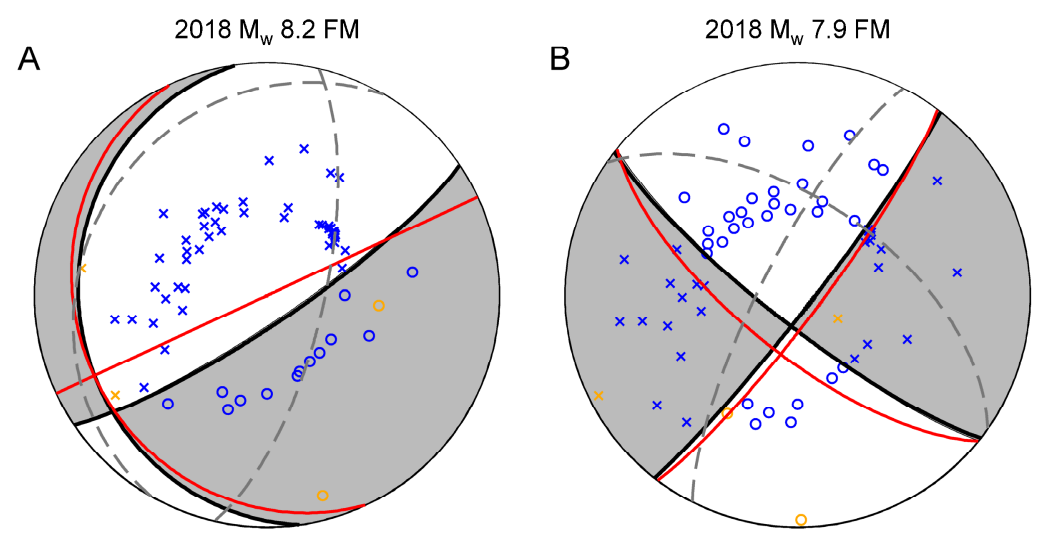

Figure 2

459 Fig. 2. First-motion focal mechanisms for (A) the $\mathbf{M}_{w} 8.2$ and (B) the $\mathbf{M}_{w} 7.9$ events. Blue

460 circles and crosses respectively indicate the positive and negative polarities from teleseismic

461 seismograms. Orange circles and crosses respectively indicate the positive and negative

462 polarities from regional seismograms. Dashed fault planes denote the best-fitting double-couple

463 focal mechanisms based on the GCMT solutions. The solid fault planes are the first-motion

464 solutions (strike, dip), $\left(172^{\circ}, 20^{\circ}\right)$ and $\left(56^{\circ}, 80^{\circ}\right)$ for the $\mathrm{M}_{\mathrm{w}} 8.2$ event, and $\left(38^{\circ}, 85^{\circ}\right)$ and $\left(128^{\circ}\right.$,

$46580^{\circ}$ ) for the $\mathrm{M}_{\mathrm{w}} 7.9$ event. Red lines indicate first subevent focal mechanisms from the subevent

466 rupture models inverted from seismic waveforms (Fig. 3). 
A

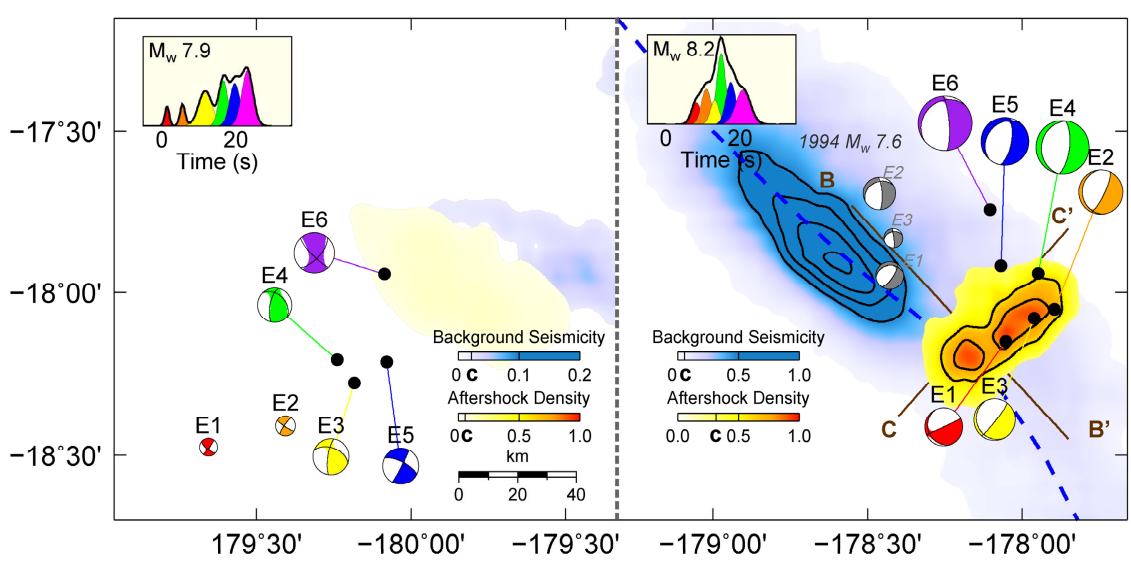

B

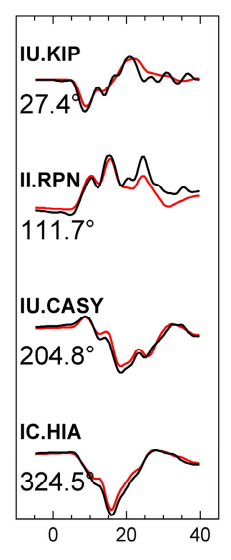

Fig. 3. Rupture processes of the 2018 Fiji doublet. (A) Subevent models for the $M_{w} 7.9$ (left half) and the $\mathrm{M}_{\mathrm{w}} 8.2$ events (right half). The black dots are centroid locations of the subevents,

471 whose moment rate functions (MRFs) are shown in the inset with the same colors as their moment tensor beach balls. Density contours of relocated aftershocks are plotted over the contours of background seismicity based on the USGS NEIC catalog. They are displayed with different color scales and truncations ("C" on the colorbars if not 0 ). The $\mathrm{M}_{\mathrm{w}} 8.2$ event initiated near the slab center (blue dashed curve as inferred from the maximum background seismicity),

476 but ruptured mostly $30 \mathrm{~km}$ to the NE by subevent E2, and E4-E6. Grey beachballs are subevent model of the 1994 Fiji $\mathrm{M}_{\mathrm{w}} 7.6$ earthquake. (B) Representative displacement waveform fits for the subevent model of the $\mathrm{M}_{\mathrm{w}} 8.2$ event at different azimuths, with data in black and synthetics in red. 
479 Early and late parts of the waveforms have opposite polarities at KIP and CASY, suggesting 480 different focal mechanisms along the rupture.

481 

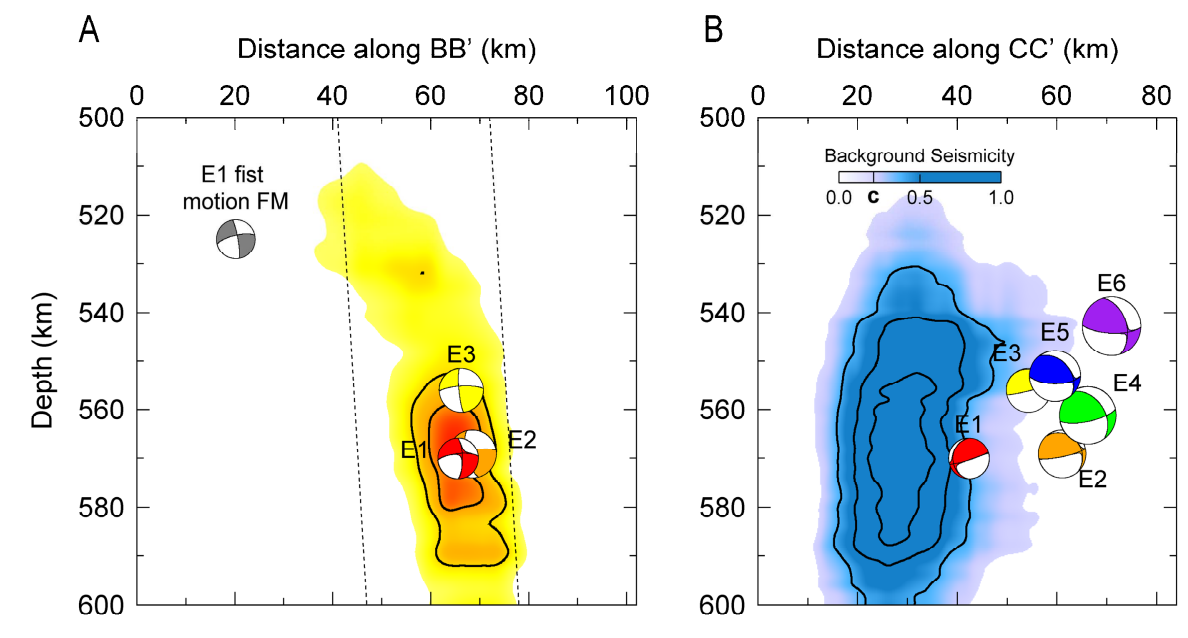

483 Fig. 4. Relation of the $\mathbf{M}_{\mathrm{w}} 8.2$ subevents with aftershocks and background seismicity. (A)

484 Cross section along BB' in Fig. 3A showing the aftershocks of $\mathrm{M}_{\mathrm{w}} 8.2$ event extend nearly 485 vertically, favoring the NE-strike fault plane for stage 1. Density contours of aftershocks are 486 displayed with same color scale as in Fig. 3A. (B) Cross section along CC' in Fig. 3A showing 487 the $\mathrm{M}_{\mathrm{w}} 8.2$ subevents spread by $30 \mathrm{~km}$ vertically and mostly away from the cold core as inferred 488 from the background seismicity density. 


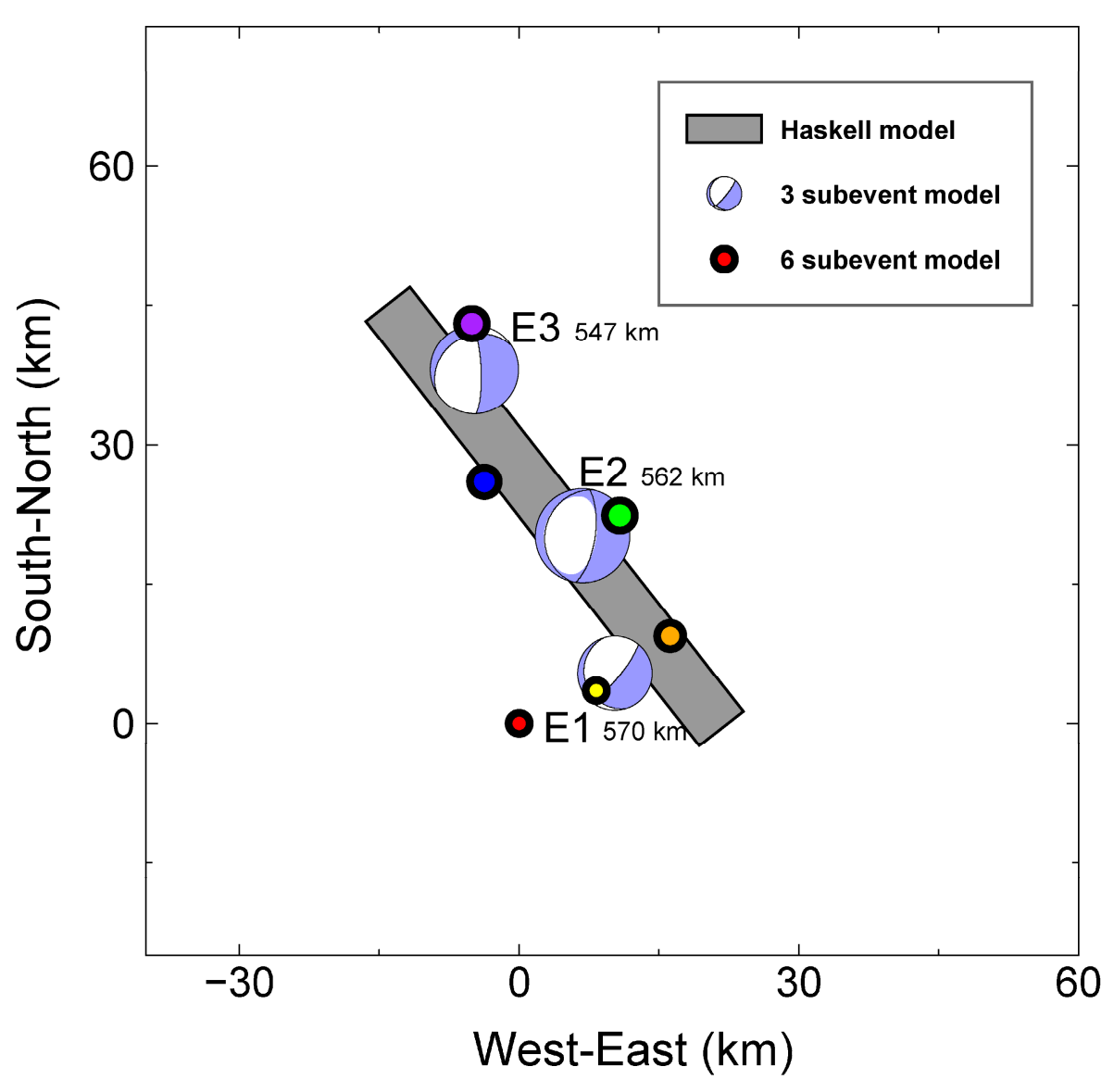

Figure 5

491 Fig. 5. Subevent models of different complexity for the $\mathbf{M}_{\mathbf{w}} \mathbf{8 . 2}$ event. The Haskell model,

492 three-subevent model, and six-subevent model are indicated by the rectangle, beachballs and

493 circles, respectively. Centroid depths of subevents for the three-subevent model are displayed.

494 These models of different levels of complexity reveal consistent overall dimension and

495 directivity of the earthquake. The three-subevent model captures the changes in focal

496 mechanisms along rupture, but not the NE strike within the first stage. Therefore, we conclude 
497 that our preferred six-subevent model does not cause artifacts due to over parameterization but

498 still capture important features of the earthquake rupture processes. Details of the Haskell model 499 and the 3-subevent model can be found in Fig. S6-S7.

500 


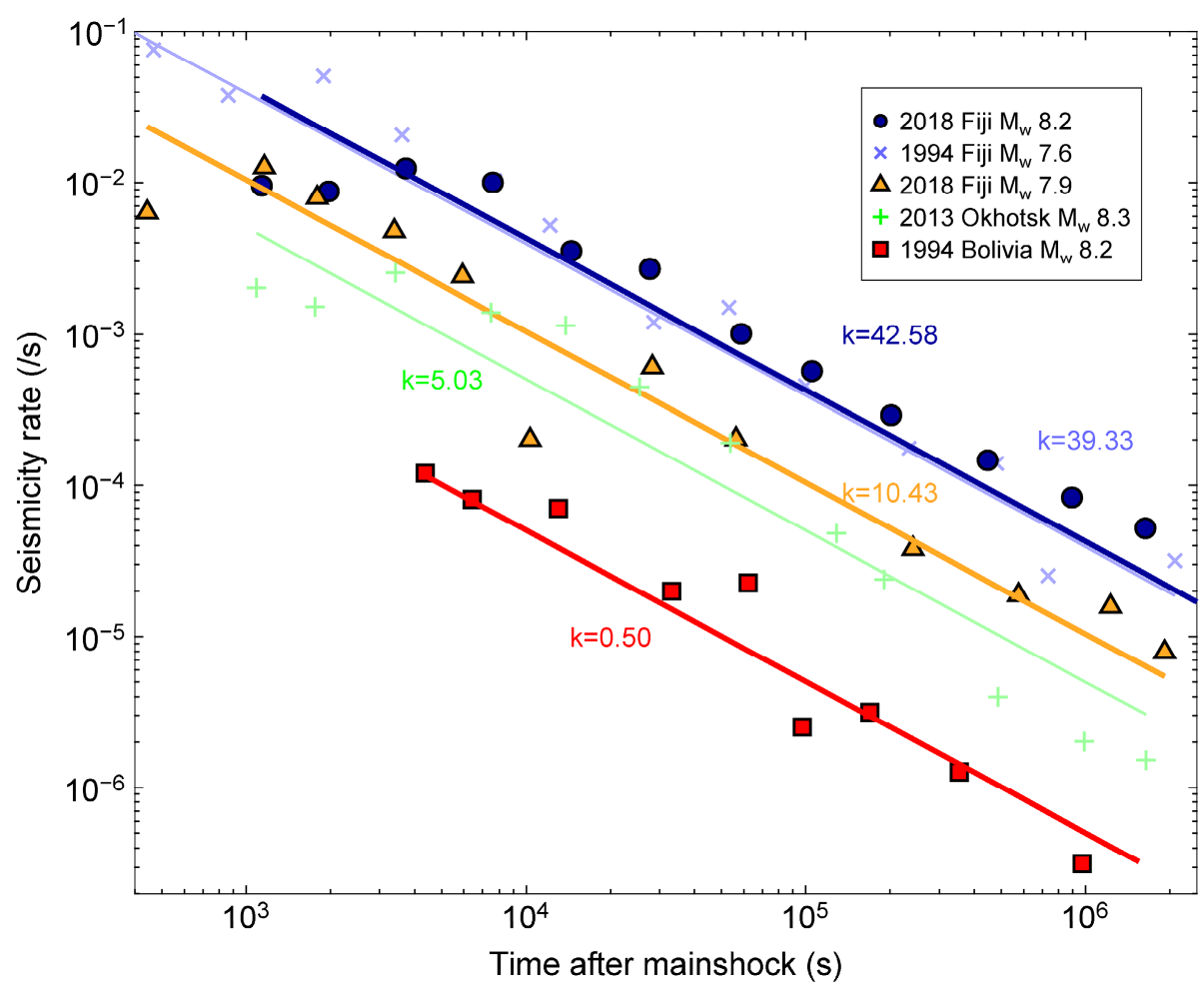

Figure 6

502 Fig. 6. Comparison of aftershock productivities of five large deep earthquakes. Aftershock

503 seismicity rates as function of time for the 2018 Fiji doublet, the 1994 Bolivia and Fiji events,

504 and the 2013 Okhotsk event based on the ISC and refined regional catalogs. The differences due to mainshock magnitude and catalog completeness have been corrected (see supplementary material for details). The aftershock catalog for the $1994 \mathrm{M}_{\mathrm{w}} 7.6$ Fiji earthquake is from Wiens and McGuire (2000), and the $1994 \mathrm{M}_{\mathrm{w}} 8.2$ Bolivian aftershocks are from Myers et al. (1995).

508 The parameter $\mathrm{k}$ represents the aftershock productivity in the Omori law $n(t)=k / t^{p}$. 


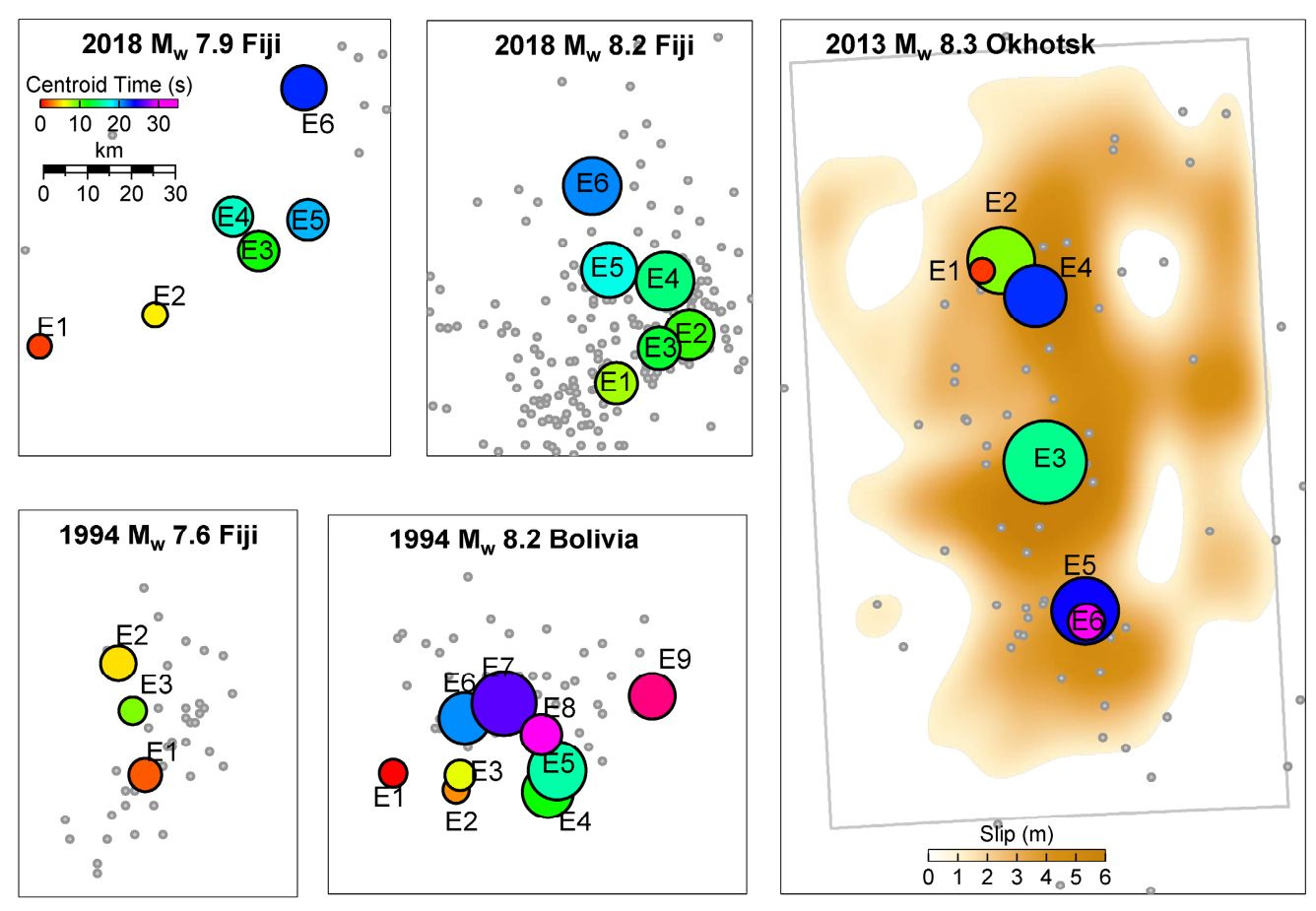

Figure 7

511 Fig. 7. Comparison of rupture dimensions of five large deep earthquakes. Subevent models

512 of the five deep events in Fig. 5 plotted at the same length scale. Color of the circles indicates

513 subevent centroid times and size represents subevent moment. Gray dots are the aftershocks in

514 one month following the mainshocks. Subevents of the Okhotsk earthquake are plotted on top of

515 a finite fault slip model (Wei et al., 2013). 
A

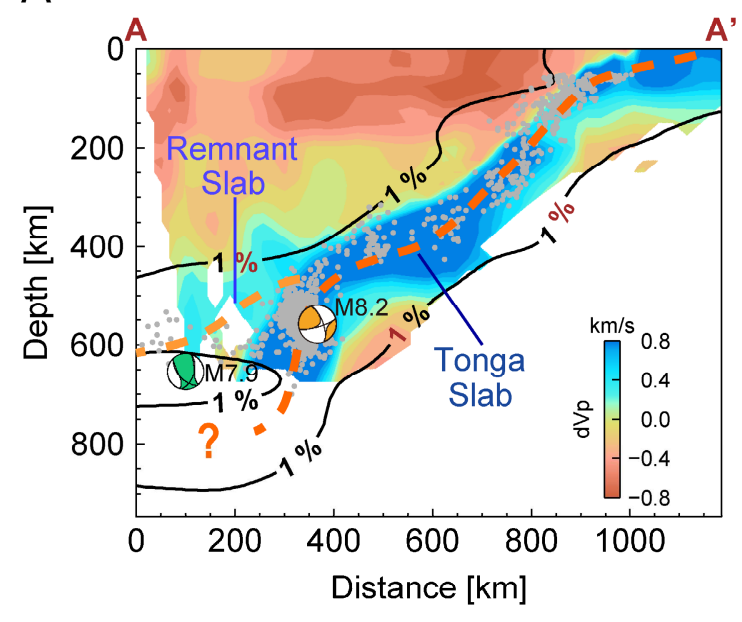

C

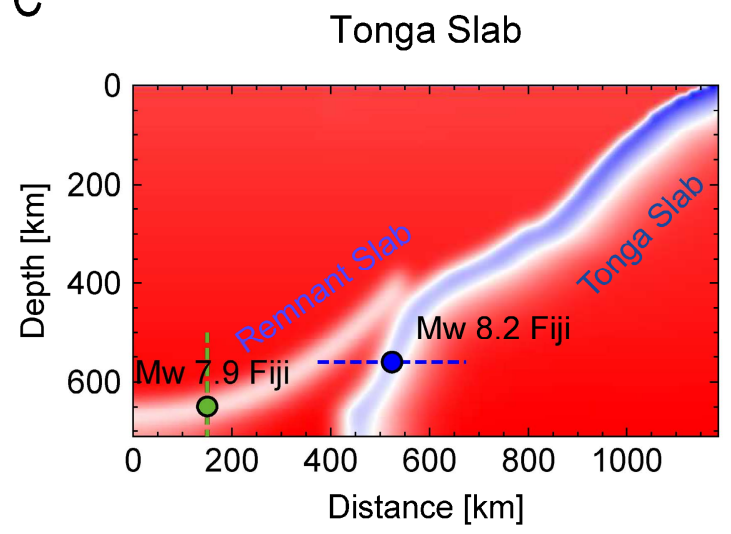

B

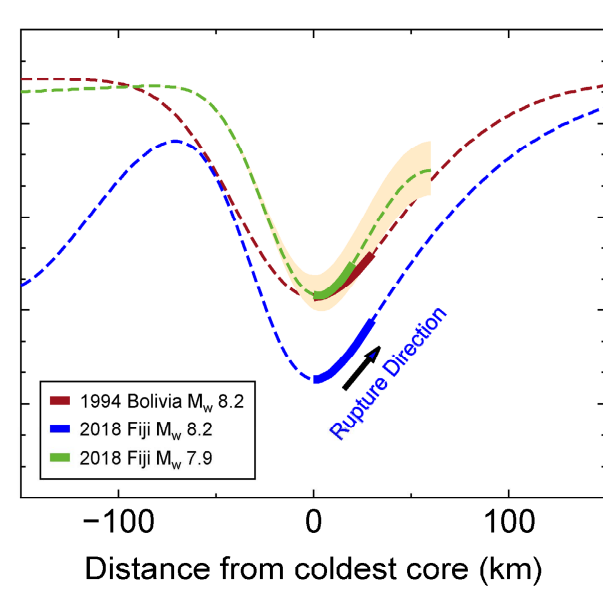

1800

1500

200

900

600

300

D

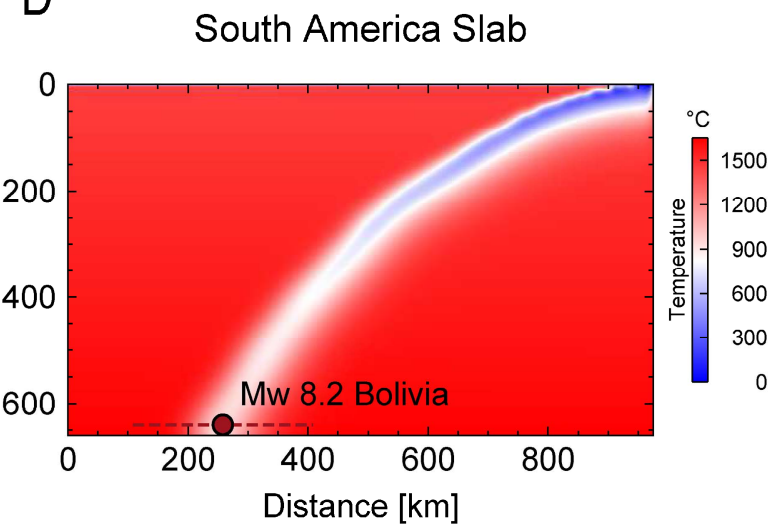

Figure 8

518 Fig. 8. Thermal modeling of the Fiji doublet. (A) Tomographic models along cross section AA'

519 in Fig. 1A, showing the Fiji doublet with respect to the Tonga slab and the inferred remnant slab.

520 The solid black lines are the $1 \% \mathrm{P}$ wave velocity anomaly contours from the GAP model (Fukao

521 and Obayashi, 2013). The background colors show the regional tomography model by Conder

522 and Wiens (2006). The gray dots are the background seismicity. (B) Slab temperature profiles

523 through three large deep earthquakes, whose approximate rupture extents are marked by thick 
524 line segments. Temperature uncertainty of the remnant slab is indicated by the shadow in light

525 yellow. (C) Simulated thermal structure for the Tonga slab and the remnant slab. The dashed

526 lines show the profiles in (B). (D) Same as (C) but for the South America slab. 